\title{
Finite element analysis of concrete filled lean duplex stainless steel columns
}

\author{
D. Lam ${ }^{\mathrm{a} *}$, J. Yang ${ }^{\mathrm{a}}$, and X.H. Dai ${ }^{\mathrm{a}}$

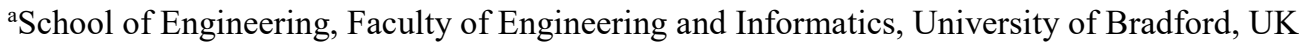 \\ *corresponding author, e-mail address: d.lam1@bradford.ac.uk
}

\begin{abstract}
In recent years, a new low nickel content stainless steel (EN 1.4162) commonly referred as 'lean duplex stainless steel' has been developed, which has over two times the tensile strength of the more familiar austenitic stainless steel but at approximately half the cost. This paper presents the finite element analysis of concrete filled lean duplex stainless steel columns subjected to concentric axial compression. To predict the performance of this form of concrete filled composite columns, a finite element model was developed and finite element analyses were conducted. The finite element model was validated through comparisons of the results obtained from the experimental study. A parametric study was conducted to examine the effect of various parameters such as section size, wall thickness, infill concrete strength, etc. on the overall behaviour and compressive resistance of this form of composite columns. Through both experimental and numerical studies, the merits of using lean duplex stainless steel hollow sections in concrete filled composite columns are highlighted. In addition, a new formula based on the Eurocode 4 is proposed to predict the cross-section capacity of the concrete filled lean duplex stainless steel composite columns subjected to axial compression.
\end{abstract}

Keywords: Lean duplex stainless steel; composite columns; axial compression; finite element model; cross-section capacity; Eurocode 4

\section{Introduction}

Concrete filled steel tubes (CFSTs) have been used for high-rise buildings and bridges throughout the world. This increase is due to their advantages in constructability and superiority in strength. CFST columns consist of steel and concrete materials acting together contributed to the higher stiffness and load bearing capacity of these columns. [1]

Austenitic stainless steel is most widely used in the construction industry, however, a recently developed 'lean duplex' stainless steel which contains only $1.5 \%$ nickel offers a cheaper alternative. The particular grade used in this study is EN 1.4162, which is generally less expensive than the austenitic counterpart but offers higher strength, while maintaining a reasonable corrosion resistance. Numerous examples of lean duplex used in the construction could be found. Theofanous and Gardner [2] carried out experimental and numerical studies on the behaviour of lean duplex stainless steel square hollow sections (SHS) and rectangular hollow sections (RHS) subjected to axial compression, to investigate the effects of the sectional shape and wall thickness to the ultimate axial capacity. It was found that lean duplex sections offer superior strength when comparing to the austenitic counterparts, which in turn, provided a significant saving to the material cost.

Huang and Young [3] conducted finite element analysis (FEA) on cold-formed lean duplex stainless steel with square and rectangular hollow sections. An accurate finite element model has been created to simulate the pin-ended cold-formed lean duplex stainless steel short columns. The results showed that Eurocode 3 [4] and the Australian / New Zealand Standard [5] are relatively conservative in predicting the axial capacity of these form of hollow sections. Even though a significant number of researchers had conducted research 
on the lean duplex stainless steel sections, there is little research had been carried out on CFST columns with lean duplex stainless steel tubes.

Lam and Giakoumelis [6] evaluated CFST columns under a variety of loading conditions with load applied: 1) on the steel and concrete simultaneously, 2) on the concrete alone and 3) on the concrete and steel with greased interface. The steel grades of S275 and S355 were used and the concrete strength varied from 30 to $100 \mathrm{MPa}$. Results shown when the concrete and steel were loaded concurrently, the tube provided less confinement by comparison to the specimens that were only loaded to the concrete core, similar findings are also reported by Sakino et al. [7].

Studies on concrete filled carbon steel rectangular hollow section (RHS) composite columns have shown that width to thickness ratio of the steel elements and the constraining factor have significant influence to the compressive axial capacity and ductility of the concrete filled columns. [8-13] Research into CFST columns with high strength concrete infill has shown that high strength concrete infill provided enhancement in strength but led to reduction in ductility. [14-16] In terms of concrete filled composite columns with stainless steel sections, Uy et al. [17] tested 72 stub and 24 slender concrete filled stainless steel columns, with concrete strength varied between 20 to $75 \mathrm{MPa}$, results on the stub column tests have shown that CFST with stainless steel tube has higher residual strength and ductile behaviour when compared to the carbon steel counterpart. An investigation into the behaviour of circular concrete filled lean duplex stainless steel tube using the finite element package ABAQUS [18] was reported by Hassanein et al. [19]. However, the FE model was validated using experimental studies on austenitic stainless steel columns carried out by Chang et al. [20] and the behaviour especially at the section capacity is quite different. It can be seen that previous research into lean duplex composite columns is relatively limited, little experimental study has been made on concrete filled composite columns with lean duplex stainless steel sections. [21] In the present study, a finite element model is developed and validated against the test results. Parametric studies were carried out over a range of concrete grades and steel thicknesses. The results of the parametric studies were used and compared with the existing design rule given in Eurocode 4 [22]. On the basis of the comparison, a new design expression based on the Eurocode 4 is proposed.

\section{Finite element model}

\subsection{General}

In this paper, finite element package ABAQUS 6.14 (RIKS method) is used to simulate the concrete filled lean duplex stainless steel stub column tests conducted by Lam et al. [21]. Geometry of the columns, materials, interactions, meshes, loading and boundary conditions of the FE model are defined accordingly and are described in the following sections.

The column specimens were subjected to concentric axial compression. Measured dimensions of the specimens are summarized in Table 1, where $t_{\mathrm{f}}, t_{\mathrm{c}}$ denote the wall thickness at flat and corner portions of the stainless steel tube. Note that the tested concrete cube strength is $35.1 \mathrm{MPa}, 61.2 \mathrm{MPa}$ and $81.0 \mathrm{MPa}$ for the C30, C60 and C80 concrete specified in Table 1 , respectively. $\mathrm{SC} 1, \mathrm{SC} 2$ and $\mathrm{SC} 3$ refer to square columns with steel tube dimensions of $60 \times 60 \times 3,80 \times 80 \times 4$ and $100 \times 100 \times 4$ (unit: $\mathrm{mm}$ ), respectively.

Table 1. Summarized measured stub column specimens dimensions in paper [21] (mm).

\begin{tabular}{cc}
\hline $\begin{array}{c}\text { Column } \\
\text { ID }\end{array}$ & $\boldsymbol{B} \times \boldsymbol{H} \times \boldsymbol{t}_{\mathbf{f}} \times \boldsymbol{t}_{\mathbf{c}} \times \boldsymbol{L}$ \\
\hline SC1-C30 & $60.18 \times 60.49 \times 3.34 \times 3.47 \times 183.5$ \\
SC1-C60 & $59.96 \times 60.34 \times 3.41 \times 3.68 \times 184.5$ \\
SC1-C80 & $59.90 \times 60.27 \times 3.12 \times 3.56 \times 184.5$ \\
SC2-C30 & $80.27 \times 80.16 \times 3.82 \times 4.19 \times 243.5$ \\
SC2-C60 & $80.30 \times 80.10 \times 3.86 \times 3.94 \times 244.5$ \\
SC2-C80 & $80.19 \times 80.42 \times 3.73 \times 4.05 \times 244.5$ \\
SC3-C30 & $102.68 \times 102.72 \times 4.26 \times 4.47 \times 304.5$ \\
SC3-C60 & $102.93 \times 102.52 \times 3.99 \times 4.42 \times 304.5$ \\
SC3-C80 & $102.85 \times 102.60 \times 4.05 \times 4.47 \times 305.0$ \\
\hline
\end{tabular}

\subsection{Steel material}

The stress-strain model used for both the flat and corner regions of the lean duplex stainless steel tube in the FE model included of two parts. The first part is linear and up to the proportional limit stress with the measured elastic modulus $E_{0}$ (listed in Table 2 , Poisson's ratio 0.3 ). The second part is a converted true stress-strain curve based on tested data, e.g. 
$0.2 \%\left(\sigma_{0.2}\right), 1 \%$ proof stresses $\left(\sigma_{1.0}\right)$, the ultimate stress $\left(\sigma_{u}\right)$ and the strain at fracture $\left(\varepsilon_{f}\right)$ by using Eqs. (1) and (2).

$\sigma_{\text {true }}=\sigma_{\text {nom }}\left(1+\varepsilon_{\text {nom }}\right)$

$\varepsilon_{l n}^{p l}=\ln \left(1+\varepsilon_{\text {nom }}\right)-\frac{\sigma_{\text {true }}}{E}$

where $\sigma_{\text {true }}$ and $\sigma_{\text {nom }}$ represent the true and engineering stress, respectively, and $\varepsilon_{l n}^{p l}$ and $\varepsilon_{\text {nom }}$ are the logarithmic plastic strain and engineering strain, respectively. The corner properties was extended to a distance of $2 \mathrm{t}$ beyond the curved portions of the stainless steel cross-sections, as suggested by Gardner and Nethercot [23].

Table 2. Measured steel material properties.

\begin{tabular}{cccccc}
\hline $\begin{array}{c}\text { Section } \\
\text { ID }\end{array}$ & $\begin{array}{c}\boldsymbol{E}_{\mathbf{0}} \\
(\mathbf{M P a})\end{array}$ & $\boldsymbol{\sigma}_{\mathbf{0 . 2}}$ & $\boldsymbol{\sigma}_{\mathbf{1 . 0}}$ & $\boldsymbol{\sigma}_{\boldsymbol{u}}$ & $\begin{array}{c}\boldsymbol{\varepsilon}_{\boldsymbol{f}} \\
(\boldsymbol{\%})\end{array}$ \\
\hline $\mathrm{S} 1_{\text {flat }}$ & 209800 & 755 & 819 & 839 & 44 \\
$\mathrm{~S}_{\text {corner }}$ & 212400 & 885 & 1024 & 1026 & 22 \\
$\mathrm{~S} 2_{\text {flat }}$ & 199900 & 679 & 736 & 773 & 42 \\
$\mathrm{~S} 2_{\text {corner }}$ & 210000 & 731 & 942 & 959 & 24 \\
$\mathrm{~S} 3_{\text {flat }}$ & 198800 & 586 & 632 & 761 & 47 \\
$\mathrm{~S}_{\text {corner }}$ & 206000 & 811 & 912 & 917 & 32 \\
\hline
\end{tabular}

\subsection{Concrete material}

The Drucker-Prager model available in ABAQUS material library was adopted to simulate the behavior of concrete core.

A three-part constitutive model was used to define the material. The first part is assumed as an elastic part up to the proportional limit which is defined as $0.5 f_{\mathrm{c}}$ (concrete cylinder strength, assumed as 0.8 times of the cube strength). The initial modulus of elasticity $E_{\mathrm{c}}$ is calculated by the empirical equation ACI Committee 318 [24] as given in Eq. (3). Poisson's ratio of concrete is taken as 0.2 . The corresponding strain $\left(\varepsilon_{\mathrm{c}}\right)$ is taken as 0.003 [23].

$$
E_{c}=4700 \sqrt{f_{c}}
$$

The second part starts from the proportional limit stress $\left(0.5 f_{\mathrm{c}}\right)$ to the concrete strength $\left(f_{\mathrm{c}}\right)$. The equation proposed by Saenz [25] was adopted shown as follows (Eq. 4).

$$
\begin{aligned}
& f=E_{c} \varepsilon /\left[1+\left(R+R_{E}-2\right)\left(\frac{\varepsilon}{\varepsilon_{c}}\right)-\right. \\
& \left.(2 R-1)\left(\frac{\varepsilon}{\varepsilon_{c}}\right)^{2}+R\left(\frac{\varepsilon}{\varepsilon_{c}}\right)^{3}\right]
\end{aligned}
$$

where $R_{E}=\frac{E_{c} \varepsilon_{c}}{f_{c}}, R=\frac{R_{E}\left(R_{\sigma}-1\right)}{\left(R_{\varepsilon}-1\right)^{2}}-\frac{1}{R_{\varepsilon}}$,

$R_{\sigma}=R_{\varepsilon}=4[26]$.
The third part is linear and starts from $f_{c}$ to $r k f_{c}$ while the corresponding strain is $11 \varepsilon_{c}$. The value of $r$ is taken as 1.0 and 0.5 for concrete with cube strength of $30 \mathrm{MPa}$ and $100 \mathrm{MPa}$, respectively, while linear interpolation is used for cube strength between 30 and 100MPa [16]. The value of $k$ can be calculated from a empirical equation given by $\mathrm{Hu}$ et al. [27] in Eq. (5).

$k=0.000178\left(\frac{B}{T}\right)^{2}-0.02492\left(\frac{B}{T}\right)+1.2722$

for $17 \ll B / T \ll 70$

\subsection{Meshes and interfaces}

Three-dimensional 8-node solid elements (C3D8) were employed to discretize the concrete-filled square stainless steel stub column models. Generally, a mesh size equals to the tube wall thickness was adopted in the flat portions of the steel columns, while minimum of 3 elements along curvature was used at corners. For concrete core, a mesh size of two times of the wall thickness was used. Two layers of meshes were used in the tube wall thickness direction.

A surface-to-surface based interaction was adopted for the contact between steel tube (slave surface) and concrete core (master surface). In the direction tangential to the surface, the 'penalty' friction with a coefficient of friction equal to 0.3 was used, while 'hard contact' was used for the normal direction. End plates were included in the model to replicate the tests. The concrete was treated as slave surface in the interactions with the end plates.

\subsection{Loading and boundary conditions}

Load was applied axially through a reference point coupled to the top end plate by displacement control method. Both ends of the stub columns were restrained against all degrees of freedom, except for the displacement in the loading direction at the top. To reduce the calculation cost, a quarter model was simulated with symmetry boundaries in two directions.

\section{Validation of the FE model}

The FE model was validated with the load vs. displacement curves, ultimate capacities and failure modes of the concrete-filled lean duplex stainless steel columns tested. The comparison of the test and FEA curves is given in Fig. 1. 
The column capacities recorded from tests and extracted from FEA is compared in Table 3. The average ratio of capacities $N_{\text {Test }} / N_{\text {FEA }}$ is 0.98 , with the standard deviation of 0.04 and the coefficient of variation (COV) of 0.044 . The value of $N_{\text {Test }} / N_{\text {FEA }}$ ranges from 0.88 to 1.02 , within a satisfactory error of $12 \%$. The failure modes observed from tests and predicted from FEA are shown in Fig. 2. It can be seen from the failure shapes and mode of failure (outwards local buckling), acceptable agreement was achieved. The developed FE model is deemed to be capable of predicting both the ultimate compressive strength and failure mode of the concrete-filled lean duplex stainless steel stub columns tested by Lam et al. [21].
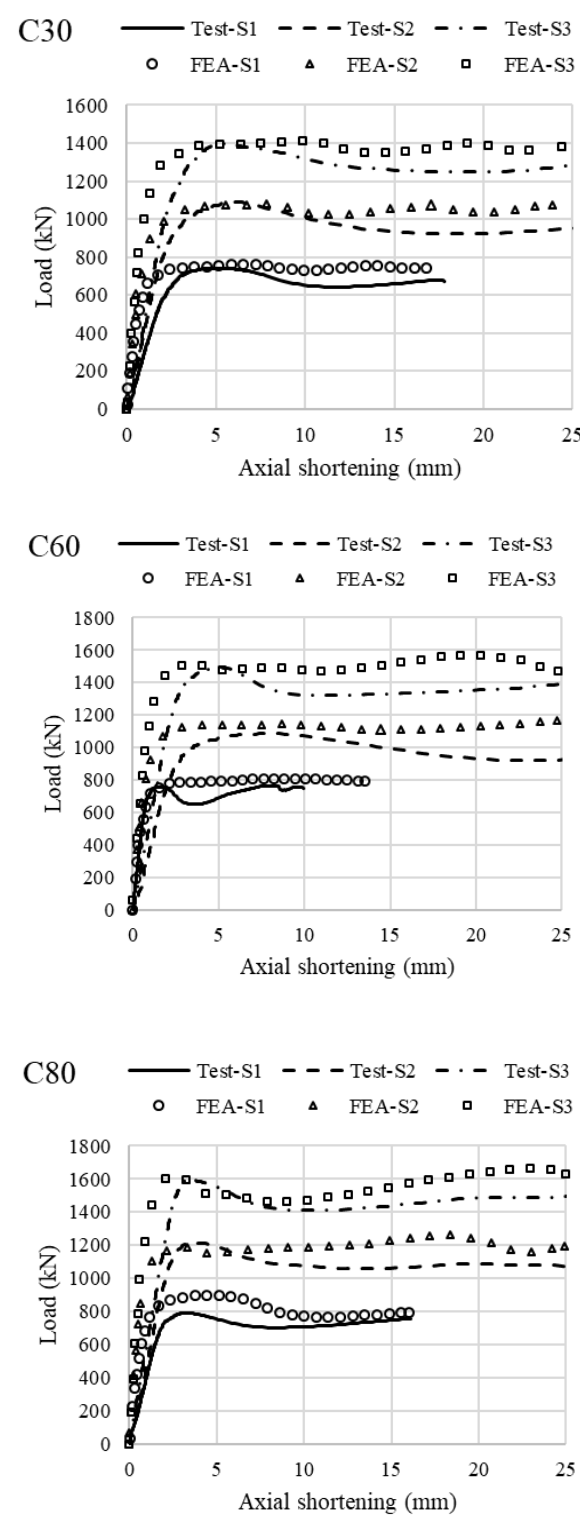

Fig. 1. Comparisons of load vs. displacement curves between test and FEA.
Table 3. Comparison of test and FEA results.

\begin{tabular}{|c|c|c|c|}
\hline $\begin{array}{c}\text { Column } \\
\text { ID } \\
\end{array}$ & $\begin{array}{l}N_{\text {Test }} \\
(\mathbf{k N})\end{array}$ & $\begin{array}{c}N_{\text {FEA }} \\
(\mathrm{kN})\end{array}$ & $\begin{array}{l}N_{\text {Test }} / \\
N_{\text {FEA }}\end{array}$ \\
\hline SC1-C30 & 739 & 761 & 0.97 \\
\hline $\mathrm{SC} 1-\mathrm{C} 60$ & 759 & 808 & 0.94 \\
\hline $\mathrm{SC} 1-\mathrm{C} 80$ & 790 & 898 & 0.88 \\
\hline $\mathrm{SC} 2-\mathrm{C} 30$ & 1105 & 1079 & 1.02 \\
\hline SC2-C60 & 1160 & 1143 & 1.01 \\
\hline $\mathrm{SC} 2-\mathrm{C} 80$ & 1220 & 1193 & 1.02 \\
\hline $\mathrm{SC} 3-\mathrm{C} 30$ & 1394 & 1414 & 0.99 \\
\hline $\mathrm{SC} 3-\mathrm{C} 60$ & 1493 & 1519 & 0.98 \\
\hline \multirow[t]{4}{*}{$\mathrm{SC} 3-\mathrm{C} 80$} & 1599 & 1614 & 0.99 \\
\hline & \multirow{2}{*}{\multicolumn{2}{|c|}{ Standard Deviation }} & 0.98 \\
\hline & & & 0.04 \\
\hline & \multicolumn{2}{|c|}{ oefficient of Variation } & 0.044 \\
\hline
\end{tabular}
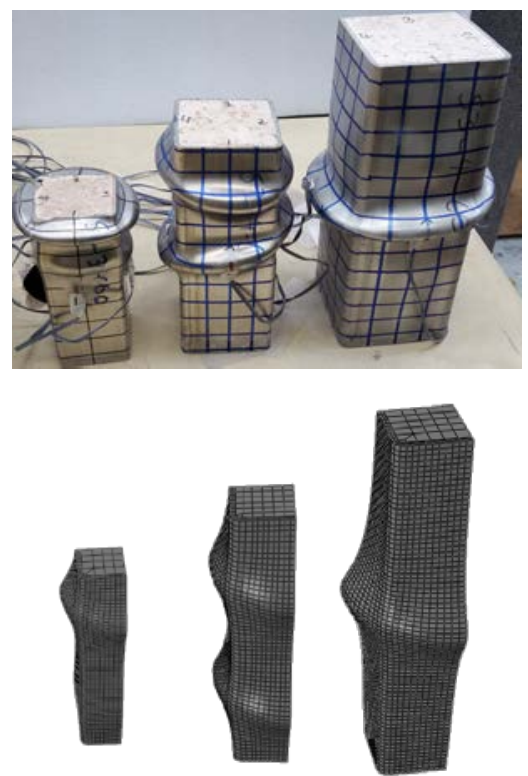

Fig. 2. Local buckling observed in both test and FEA results.

\section{Parametric study}

\subsection{Parameters}

A preliminary parametric study was carried out by using the validated FE model. A total of 24 stub column models were considered to assess the effect of concrete cylinder strength and steel tube cross-sectional geometry on the overall behaviour of the concrete-filled lean duplex stainless steel stub columns.

Table 4 summarizes the characteristics of the models. Overall 8 cross-sections were selected, ranging from $60 \times 60 \times 3$ to $150 \times 150 \times 5$, among which the ratio of outer width to tube wall thickness $\left(\mathrm{B} / t_{\mathrm{f}}\right)$ varies from 20 to 40 . The length of all the stub columns was equal to $3 B$. 
Adopted concrete cylinder strength is $30 \mathrm{MPa}$, $60 \mathrm{MPa}$ and $80 \mathrm{MPa}$ for each cross-section. In the parametric study, steel properties given in Table 2 for S1, S2 and S3 were used for crosssections $60 \times 60 \times 3,80 \times 80 \times 4$ and $100 \times 100 \times 4$, respectively. The properties of S1 were also used for cross-sections $100 \times 100 \times 3$ and $120 \times 120 \times 3$, and S3 for $120 \times 120 \times 4$ and $150 \times 150 \times 5$

Table 4. Details of concrete-filled lean duplex stainless steel stub columns considered in the parametric study.

\begin{tabular}{cccc}
\hline Model ID & Concrete & $\boldsymbol{B} / \mathbf{t}_{\mathbf{f}}$ & $\begin{array}{c}\boldsymbol{N}_{\text {sc }} \\
(\mathbf{k N})\end{array}$ \\
\hline $60 \times 60 \times 3$ & $\mathrm{C} 30 / 60 / 80$ & 20 & $682 / 748 / 784$ \\
$80 \times 80 \times 4$ & $\mathrm{C} 30 / 60 / 80$ & 20 & $1114 / 1231 / 1299$ \\
$100 \times 100 \times 3$ & $\mathrm{C} 30 / 60 / 80$ & 33.3 & $1217 / 1443 / 1601$ \\
$100 \times 100 \times 4$ & $\mathrm{C} 30 / 60 / 80$ & 25 & $1306 / 1500 / 1634$ \\
$100 \times 100 \times 5$ & $\mathrm{C} 30 / 60 / 80$ & 20 & $1593 / 1818 / 1970$ \\
$120 \times 120 \times 3$ & $\mathrm{C} 30 / 60 / 80$ & 40 & $1472 / 1837 / 2087$ \\
$120 \times 120 \times 4$ & $\mathrm{C} 30 / 60 / 80$ & 30 & $1606 / 1937 / 2170$ \\
$150 \times 150 \times 5$ & $\mathrm{C} 30 / 60 / 80$ & 30 & $2510 / 3027 / 3390$ \\
\hline
\end{tabular}

\subsection{Effect of concrete cylinder strength and section size}

Fig. 3 shows the axial capacities of the columns increased with the increasing of concrete cylinder strength. The bigger the section size, the higher the increment. In other words, the capacity enhancement was more significant for the cross-section $120 \times 120 \times 3$ than $60 \times 60 \times 3$. This phenomenon resulted from the contributions of both the enlarged crosssectional area of the tube and the amount of concrete infill.

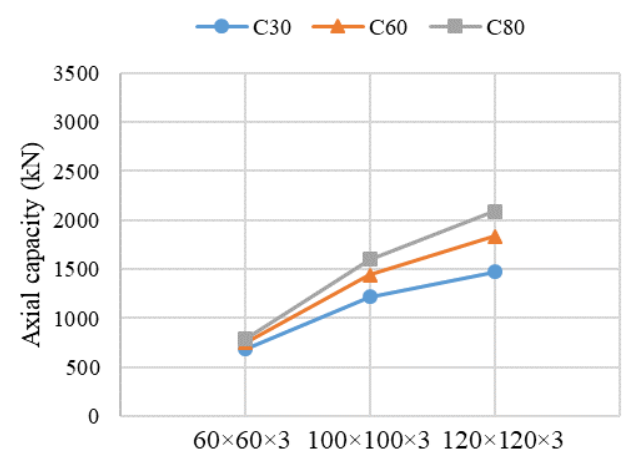

Fig. 3. Effect of cylinder strength and section size on axial compressive capacities of concrete-filled lean duplex stainless steel stub columns.

\subsection{Effect of tube wall thickness}

By maintaining the section size, the effect of tube wall thickness on the ultimate capacities of the columns was revealed, as shown in Fig. 4. The axial compressive capacity of the columns appeared to rise with the increasing of the tube wall thickness. The increase of the column capacity was more notable after the tube wall thickness was thicker than, i.e. $4 \mathrm{~mm}$ in this case.

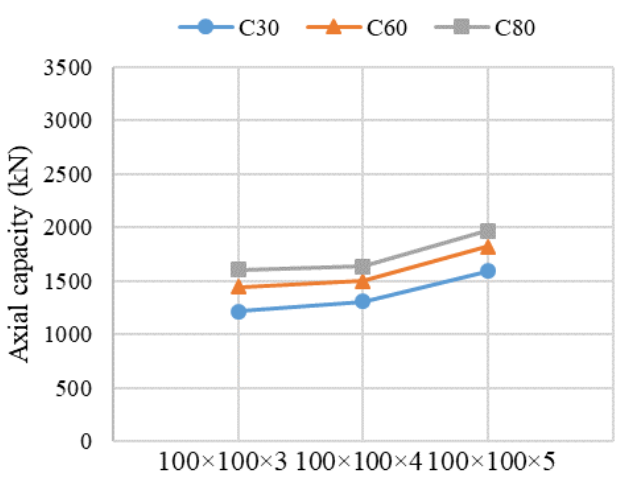

Fig. 4. Effect of tube wall thickness on axial compressive capacities of concretefilled lean duplex stainless steel stub columns.

\section{Prediction of axial compacity}

The design equation, Eq. (6), provided in Eurocode 4 for concrete-filled carbon steel tube columns was firstly used to calculate the axial compressive capacities of the columns analyzed in the parametric study. The results showed that Eq. (6) for concrete filled carbon steel tube columns underestimated the axial capacity of the composite concrete filled columns with lean duplex stainless steel sections. Eq. (7) was then proposed for the prediction of the axial compressive capacity of concrete-filled lean duplex stainless steel columns. Eqs. (6)-(7) are given as follows,

$$
N_{E C 4}=A_{s} f_{y}+A_{c} f_{c k}
$$

where

$A_{\mathrm{s}}$ is the cross section area of the steel section;

$f_{\mathrm{y}}$ is the yield stress of the steel section;

$A_{\mathrm{c}}$ is the cross section area of the concrete;

$f_{\text {ck }}$ is the cylinder strength of the concrete.

$$
N_{\text {prop }}=A_{s} \sigma_{1.0}+\varphi A_{c} f_{c k}
$$

where

$\sigma_{1.0}$ is the steel strength at $1.0 \%$ strain;

$\varphi$ is the confinement coefficient for the infilled concrete. 
In this study, the confinement coefficient $(\varphi)$ for the concrete infill is taken as 1.1 for simplicity. Table 5 shows the comparison of the parametric results vs. the new proposed design equation. The average ratio of capacities $N_{\text {para }} / N_{\text {prop }}$ is 1.00 , with the standard deviation of 0.05 and COV of 0.053 . The average value of (for each cross-section with different concrete strengths) $N_{\text {sc }} N_{\text {prop }}$ ranges from 0.93 to 1.08 , within a satisfactory average error of $8 \%$.

Table 5. Comparison of parametric results vs. proposed design equation.

\begin{tabular}{ccc}
\hline Model ID & $\begin{array}{c}\boldsymbol{N}_{\text {prop }} \\
(\mathbf{k N})\end{array}$ & $\boldsymbol{N}_{\text {sc }} / \boldsymbol{N}_{\text {prop }}$ \\
\hline $60 \times 60 \times 3$ & $637 / 733 / 797$ & 1.02 \\
$80 \times 80 \times 4$ & $1035 / 1206 / 1320$ & 1.03 \\
$100 \times 100 \times 3$ & $1226 / 1517 / 1711$ & 0.96 \\
$100 \times 100 \times 4$ & $1224 / 1502 / 1688$ & 1.01 \\
$100 \times 100 \times 5$ & $1427 / 1693 / 1871$ & 1.08 \\
$120 \times 120 \times 3$ & $1559 / 1988 / 2274$ & 0.93 \\
$120 \times 120 \times 4$ & $1560 / 1974 / 2250$ & 0.99 \\
$150 \times 150 \times 5$ & $2438 / 3084 / 3515$ & 0.99 \\
\cline { 2 - 3 } & Average & 1.00 \\
& Standard Deviation & 0.05 \\
Coefficient of Variation & 0.053 \\
\hline \multicolumn{3}{c}{}
\end{tabular}

\section{Conclusions}

Finite element analysis of concrete filled lean duplex stainless steel columns subjected to concentric axial compressive load was conducted in this paper. A finite element model was developed and validated through comparisons of the results obtained from the experimental study. A parametric study was then carried out to examine the effect of concrete cylinder strength, section size and tube wall thickness on the compressive capacity of the composite columns. Through both experimental and numerical studies, the merits of using lean duplex stainless steel hollow sections in concrete filled composite columns are highlighted. A new formula based on the Eurocode 4 is proposed to predict the crosssection capacity of the concrete filled lean duplex stainless steel composite columns subjected to axial compression. The results showed that the proposed equation could predict the axial capacity of concrete filled lean duplex stainless steel columns.

\section{References}

[1] Lam D, Gardner L. Structural design of stainless steel concrete filled columns. Journal of
Constructional Steel Research 2008; 64(11):1275-1282.

[2] Theofanous M, Gardner L. Testing and numerical modelling of lean duplex stainless steel hollow section columns. Journal of Engineering Structures 2009; 31(12):30473058.

[3] Huang Y, Young B. Structural performance of cold-formed lean duplex stainless steel columns. Thin-Walled Structures 2014; 83: 59-69.

[4] CEN. Eurocode 3: EN1993-1-4 - Design of steel structures - Part 1.4: General rules Supplementary rules for stainless steels. European Committee for Standardization; 2006.

[5] Australian / New Zealand Standard: AS/NZS 4673:2001. Cold-formed stainless steel structures. Standards Australia, Sydney, Australia; 2001.

[6] Giakoumelis G, Lam D. Axial capacity of circular concrete-filled tube columns. Journal of Constructional Steel Research 2004; 60(7):1049-1068.

[7] Sakino K, Tomii M, Watanabe K. Sustaining load capacity of plain concrete stub columns by circular steel tubes. In: Conference on concrete filled steel tubular construction 1998; 112-18.

[8] Uy B. Local and post-local buckling of concrete filled steel welded box columns. Journal of Constructional Steel Research 1998; 47(1-2):4772.

[9] Uy B. Strength of short concrete filled high strength steel box columns. Journal of Constructional Steel Research 2001; 57(2):113134.

[10]Han L, Yao G. Influence of concrete compaction on the strength of concrete-filled steel RHS columns. Journal of Constructional Steel Research 2003; 59(6):751-767.

[11] Mursi M, Uy B. Strength of concrete filled steel box columns incorporating interaction buckling. Journal of Structural Engineering 2003; 129(5):626-639.

[12]Lam D, Williams C. Experimental study on concrete filled square hollow sections. Steel and Composite Structures 2004; 4(2):95-112.

[13] Han L. Tests on stub columns of concrete-filled RHS sections. Journal of Constructional Steel Research 2002; 58(3):353-372.

[14] Rangan BV, Joyce M. Strength of eccentrically loaded slender steel tubular columns filled with high-strength concrete, ACI Structural Journal 1992; 89 (b):676-681.

[15]Kilpatrick AE, Rangan BV. Tests on highstrength composite concrete columns. Research Report No1/97, School of Civil Engineering, University of Technology, Western Australia; 1997. 
[16]Ellobody E, Young B, Lam D. Behaviour of normal and high strength concrete-filled compact steel tube circular stub columns. Journal of Constructional Steel Research 2006; 62(7):706-715.

[17] Uy B, Tao Z, Han L. Behaviour of short and slender concrete-filled stainless steel tubular columns. Journal of Constructional Steel Research 2011; 67(3):360-378.

[18]ABAQUS. Analysis user's manuals and example problems manuals, version 6.9. Providence, Rhode Island: Abaqus Inc.; 2013.

[19] Hassanein M, Kharoob O, Liang Q. Behaviour of circular concrete-filled lean duplex stainless steel-carbon steel tubular short columns. Engineering Structures 2013; 56:83-94.

[20]Chang X, Ru ZL, Zhou W, Zhang Y-B. Study on concrete-filled stainless steel-carbon steel tubular (CFSCT) stub columns under compression. Thin-Walled Structures 2013; 63:125-33.

[21] Lam D Yang J, Mohammed A. Axial Behaviour of Concrete Filled Lean Duplex Stainless Steel
Square Hollow Sections, Eurosteel 2017, Copenhagen, Denmark; 2017.

[22]CEN. EN 1994-1-1: Eurocode 4 - Design of composite steel and concrete structures. Part 11: General rules and rules for buildings. European Committee for Standardization; 2004.

[23] ACI 318-95. Building code requirements for structural concrete and commentary. Detroit (USA): American Concrete Institute; 1999.

[24] Saenz LP. Discussion of equation for the stressstrain curve of concrete. Journal of American Concrete Institute 1964; 61:1229-1235.

[25] Hu HT, Schnobrich WC. Constitutive modeling of concrete by using nonassociated plasticity. Journal of Materials in Civil Engineering 1989; 1(4):199-216.

[26] Hu HT, Huang $\mathrm{CH}, \mathrm{Wu} \mathrm{MH}, \mathrm{Wu}$ YM. Nonlinear analysis of axially loaded concretefilled tube columns with confinement effect. Journal of Structural Engineering, ASCE 2003; 129(10):1322-1329. 